\title{
SERO-COMPARATIVE STUDY OF RHINOPNUMINITIS (EQUINE HERPES SEROTYPES 1/4) IN SOME REGIONS OF NORTH, MIDDLE AND SOUTH OF SYRIA
}

\author{
HAZEM ALTAWEEL ; ABDUL KARIM KAHLB ALLOZ ${ }^{* *}$ and MUHAMAD ZUHIR ALAHMAD ${ }^{* * *}$ \\ ${ }^{*}$ Master in the Department of Animal Diseases - infectious diseases \\ ${ }^{* *}$ Professor in the Department of Internal and Infectious Medicine and poultry \\ *** Doctor in the department of surgery and Obstetrics \\ Email: dr.hazem.taweel@hotmail.com
}

\section{ABSTRACT}

Received at: $30 / 4 / 2014$

Accepted: 21/5/2014
In this study, Indirect Enzyme-linked Immune Sorbent Assay (ELISA) was performed to detect specific antibodies of equid herpes in the North, Middle and South of Syria and determine the serotype of the injury of the typical virus serotypes ( 1 and 4) in samples of blood collected from 145 horses (horse - mare - foal) non vaccinated against EHV 1/4 spread at three areas, using the enzyme immunoassay test (indirect ELISA). The serotype EHV1 serotype causes abortion in horses It also causes respiratory and neurological disorders, while the EHV4 serotype responsible for respiratory disorders. The prevalence serotypel (EHV1) in the southern region $4 \%$ in the middle region $8 \%$, while in the northern region was $2.2 \%$, The study showed serological prevalence serotype 4 (EHV4) in the southern region by $98 \%$ in the middle region $88 \%$, while in the northern region was $93.3 \%$.

Keywords: Sero-Comparative, Rhinopnuminitis, Syria.

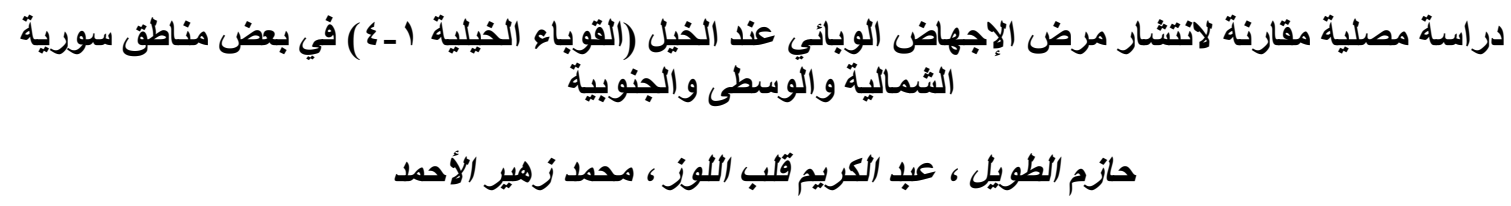

Email: dr.hazem.taweel@hotmail.com

تم في هذه الدر اسة استخدام تقنية الإليزا المطورة للكثف عن الكئ الأضداد النوعية للقوباء الخيلية في مناطق الدراسة وتحديد النمط المصلي للإصابة

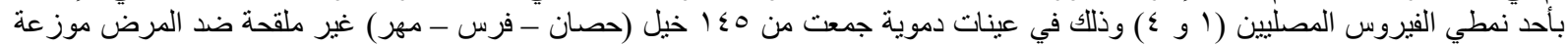
على ثلاث مناطق رئيسية في سورية وذلك باستخدام إختبار المقايسة المناعية الأنزيمية غير المباثئ (الثرة (الإليز ا غير المباثرة).

يعتبر النمط المصلي' (EHV1) من الأمر اض المجهضة للخيل كما أنه يسبب اضطر ابات تتفسية وعصبية في حين أن النمط المصلي؛ (EHV4) يكون مسئو لا عن الاضطظر ابات التنفسية.

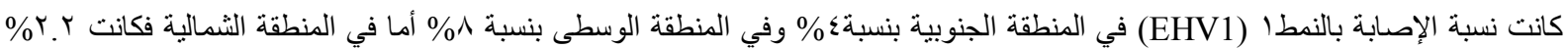

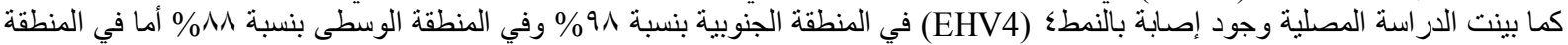

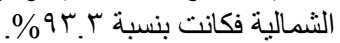

\section{INTRODUCTION المقدمـة}

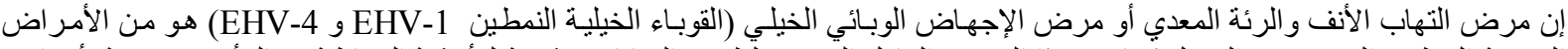

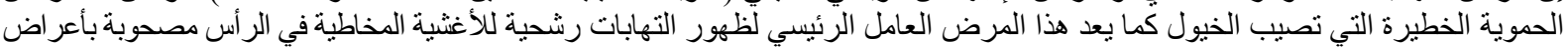

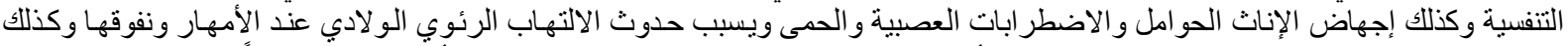

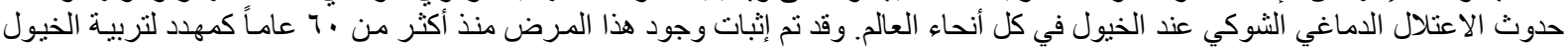

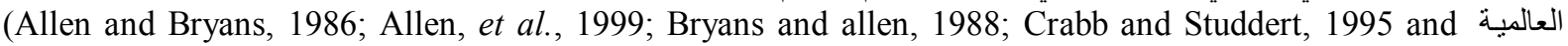
O’Callaghan et al., 1983)

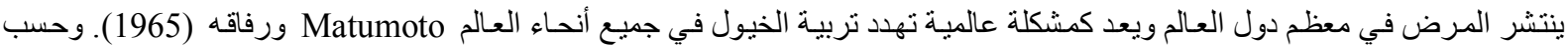

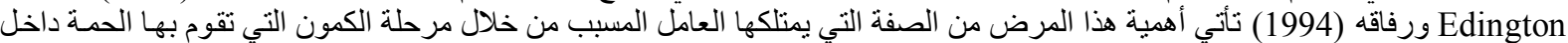
جسم الحيو ان المصاب و وعودة الأعر اض بعد فترة من الثفاء. 
ينتقل المرض عن طريق التماس المباثر بين الحيو انات المصابة و السليمة أو الحيوانات الحاملة للمرض. كما ينتقل عن طريق التماس غير المباثر

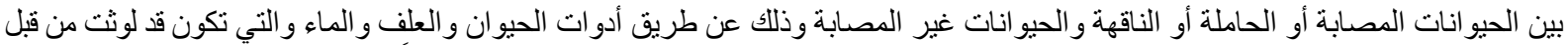

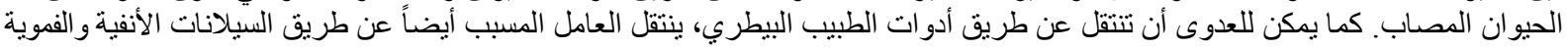

.(Doll and Bryans, 1963; Allen and Bryans, 1986)

وقد لوحظ أن العدوى الكامنة تعود للنشاط بعد تعرض الحيو ان الذي يحمل الإصابة للإجهاد. و الأفر اس الدصابة بعدوى كامنة تكون مصدراً لإصابة

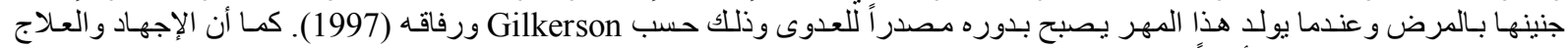
بالستيروئيدات القترية يؤدي أيضاً إلى تنتيط الحمة وعودة العدوى من جديد (Welch et al.,1992; Slater, 2007).

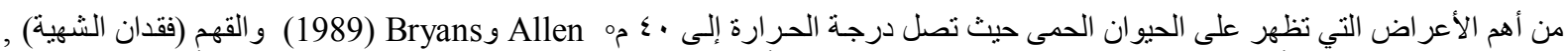
الم كtuddert

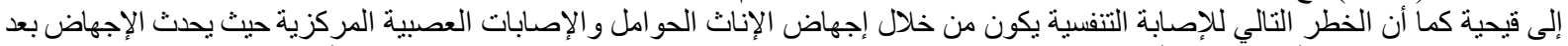

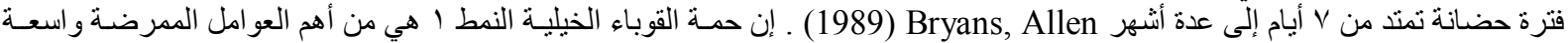

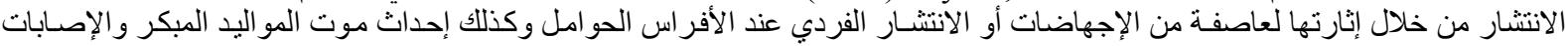

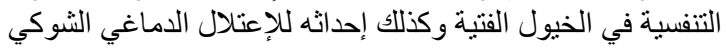

(Patel and Heldens, 2005; Reed and Toribio, 2004; Van Maanen, 2002).

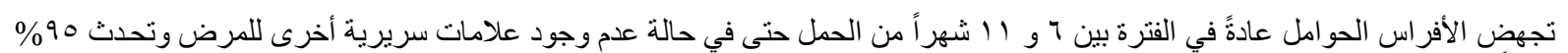

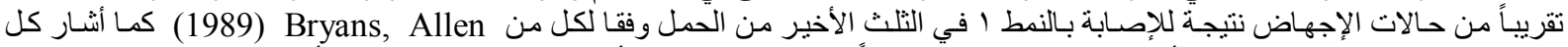

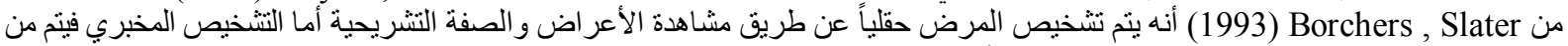

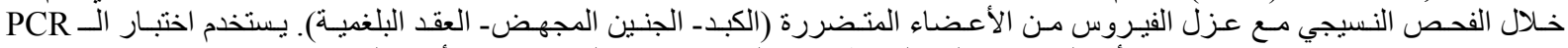
(Polymerase Chaine Reaction)

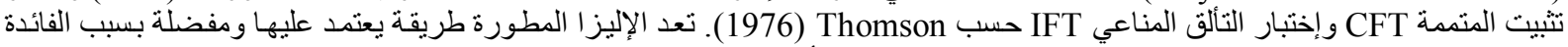
التطبيقية لهذا الإختبار وحساسيته بالمقارنة مع الاختبار ات المصلية الأخرى

(Crabb and Studdert, 1993; Crabb and Studdert, 1995; Yasunaga et al., 2000; Hartley et al., 2005).

\section{OBJECTIFS}

\section{أ هداف البحث}

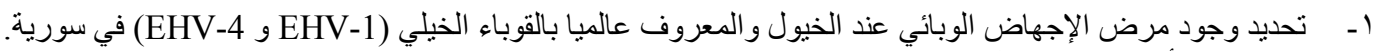

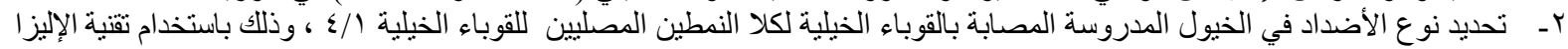
المطورة. r- مقارنة الإنتشار المصلي للأضداد النوعية للقوباء الخيلية النمطين / ع في مناطق الدراسة.

\section{MATERIALS and METHODS مواد وطرائق العمل}

في دراستتا هذه تم أخذ العينات من مز ارع خيول متخصصة بتربية أفراس التكاثر ونو ادي الخيل المتخصصة بتربية خيول الققز والرياضة المختلفة

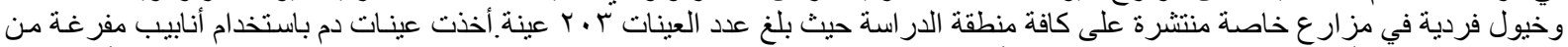

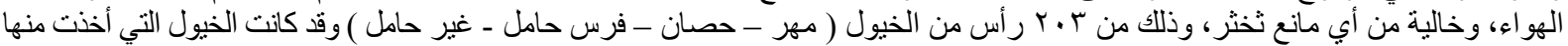

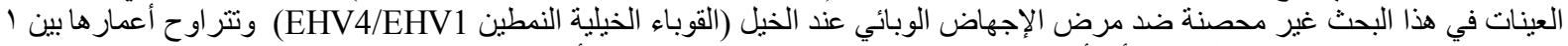

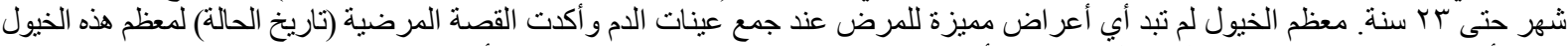

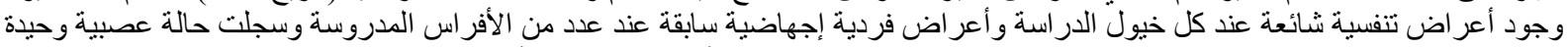

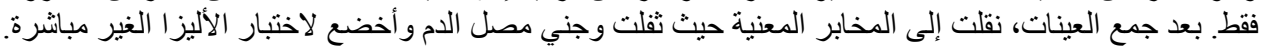

اختبار المقايسة المناعية المرتبط بالإنزيم ELISA ونكار

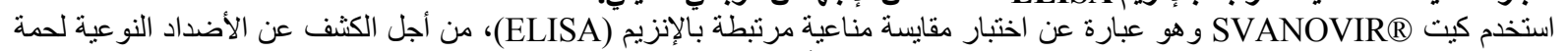

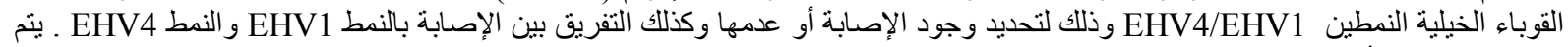
الكثف عن هذه الأضداد النوعية في المصل و البلازما عند الخيول.

\section{RESULTS \\ النتائسج}

الانتشار المصلي للإصابة بالحمة الحلئية الخيلية (1 و ع ؛ ) عند الخيل في المنطقة الجنوبية:

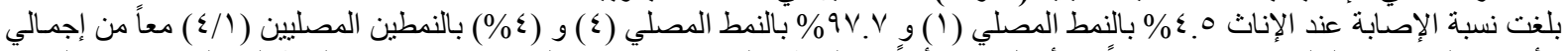

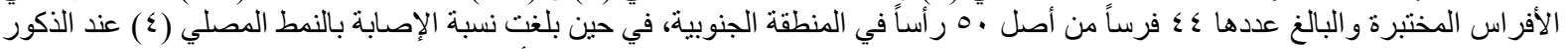

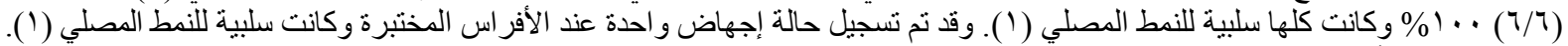

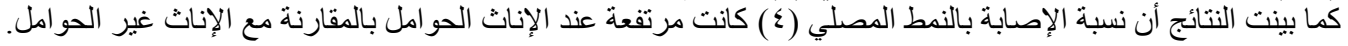


$\underline{\text { Assiut Vet. Med. J. Vol. } 60 \text { No. } 142 \text { July } 2014}$

الجدول رقم ا: الانتثار المصلي للحالات الإيجابية والمشتبهة ونسب الإصابة بالحمة الحلئية الخيلية ( و ع ؛) عند الخيول المختبرة في المنطقة الجنوبية من سورية.

\begin{tabular}{|c|c|c|c|c|c|c|c|c|c|}
\hline 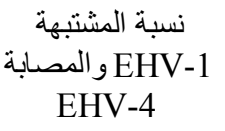 & المجباتة & الحواملة الإناث & 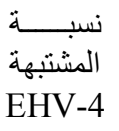 & نسبـــــة & $\begin{array}{c}\text { نسبــــة الإصـابة } \\
\text { EHV-1/4 }\end{array}$ & 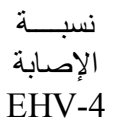 & نسبـــة & العينات & \\
\hline צו. \%) & \% & $\%$ rq & - & דץ. ו'0 & $\% \leqslant .0 \leqslant$ & $\% 9 \vee . \vee$ & $\% \leqslant 0$ & $\varepsilon \varepsilon$ & الإناث \\
\hline \multirow[t]{2}{*}{. } & - & . & . & - & - & $\% 1 \ldots$ & - & 7 & الذكور \\
\hline & & & & & & & & 0. & الكلي \\
\hline
\end{tabular}

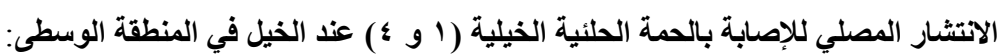

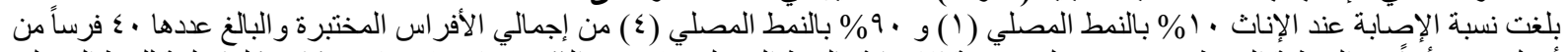

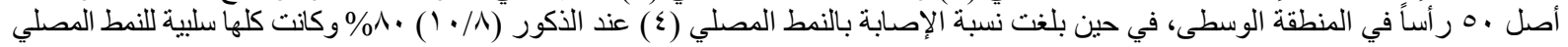

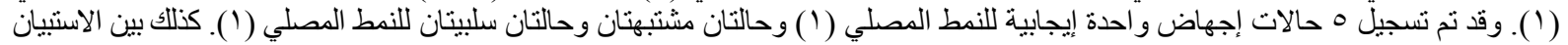

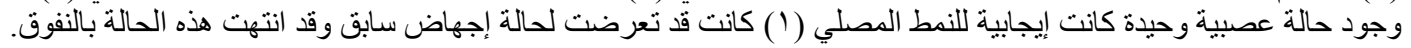

الجدول رقم Y: الانتشار المصلي للحالات الايجابية والمشتبهة ونسب الإصابة بالحمة الحئية الخيلية (ا و ع ) عند الخيول المختبرة في المنطقة الوسطى من سورية.

\begin{tabular}{|c|c|c|c|c|c|c|c|c|c|}
\hline نسبة المشتبهة & نسبة & نسبة & نسبــــــة & نسبــــــة & نسبـــــة & نسبـــة & نسبــــة & عدد & \\
\hline EHV-1 & الإناث & الإناث & المشتبهة & المشتبهة & الإصـابة & الإصـابة & الإصابة & العينات & \\
\hline و المصـابة4E-4V & المجهضة & الحوامل & EHV-4 & EHV-1 & $\mathrm{EHV}-1 / 4$ & EHV-4 & EHV-1 & & \\
\hline$\% 1 Y .0$ & $\%$ & $\cdot$ & $\cdot$ & $\% 1 Y .0$ & $\% 1$ & $\% 9$ & $\% 1$ & $\varepsilon$. & الإناث \\
\hline \multirow[t]{2}{*}{$\cdot$} & $\cdot$ & - & - & $\cdot$ & $\cdot$ & $\%{ }^{\wedge}$. & $\cdot$ & $1 \cdot$ & الذكور \\
\hline & & & & & & & & 0 . & الكلي \\
\hline
\end{tabular}

الانتثار المصلي للإصابة بالحمة الحلئية الخيلية (1 و \& ) عند الخيل في المنطقة الثمالية:

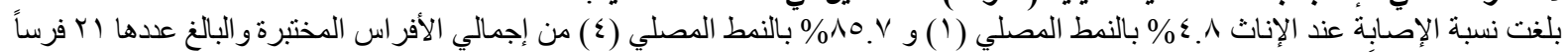

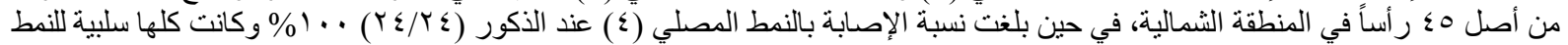

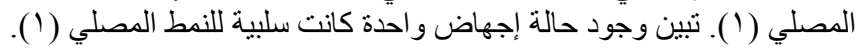

الجدول رقم بّ: الانتشار المصلي للحالات الإيجابية و المشتبهة ونسب الإصابة بالحمة الحلئية الخيلية (1 و ع) عند الخيول المختبرة في المنطقة الثمالية من سورية.

\begin{tabular}{|c|c|c|c|c|c|c|c|c|c|}
\hline 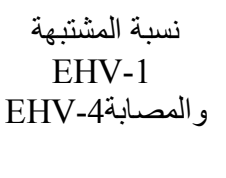 & المجهبة & الحوالثة & نسبـــــــة & 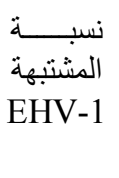 & 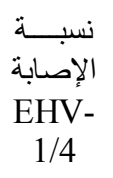 & 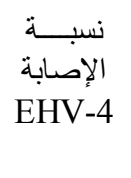 & نسبــــة & العينات & \\
\hline . & $\% \leqslant . \vee \neg$ & - & $\% 9.0 Y$ & • & $\% \leqslant . \vee 4$ & $\% \wedge 0 . \vee 1$ & $\% \leqslant . \vee 4$ & YI & الإناث \\
\hline \multirow[t]{2}{*}{$\% \leqslant .17$} & . & - & . & $\%\{.17$ & . & $\% 1 \ldots$ & . & $r \leq$ & الذكور \\
\hline & & & & & & & & $\leq 0$ & الكلي \\
\hline
\end{tabular}

The Sampling Distribution of the Proportion

التحليل الإحصائي للنتائج: استخدمنا في التحليليل الإحصائي لهذا المسح نوزيع المعاينة للنسبة:

المنطقة الجنوبية:

$(\mathrm{SEp} 1=0.03)(0-0.1$, CI 95\%)

(SEp4=0.02)(0.94 - 1.0, CI 95\%)

المنطقة الوسطى:

$(\mathrm{SEp} 1=0.04)(0-0.16$, CI 95\%) $(\mathrm{SEp} 4=0.04)(0.82-0.98$, CI 95\%) المنطقة الثمالية:

$(\mathrm{SEp} 1=0.02)(0-0.06$, CI 95\%) $(\mathrm{SEp} 4=0.04)(0.85-1.0$, CI 95\%) 


\section{DISCUSSION}

المناقشة

إن المسوحات السابقة للكثف عن المرض و التي استعانت بالاختبار ات المصلية مثل إختبار تثبيت المتمدة واختبار التعادل المصلي لم تقلح في تحديد

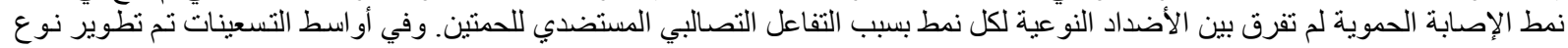

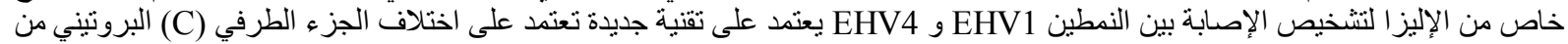

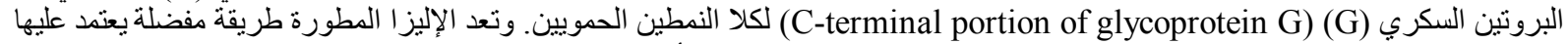

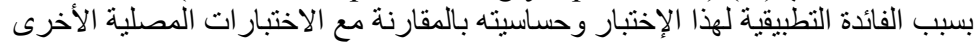
(Crabb and Studdert, 1993; Crabb and Studdert, 1995; Yasunaga, et al., 2000; Hartley et al., 2005)

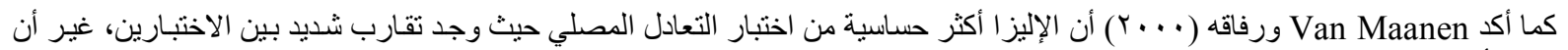

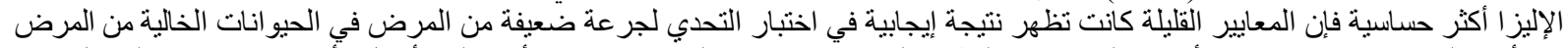

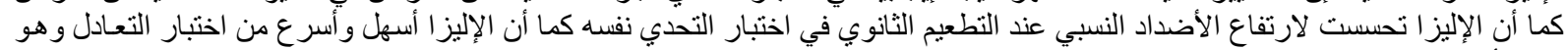

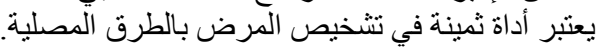

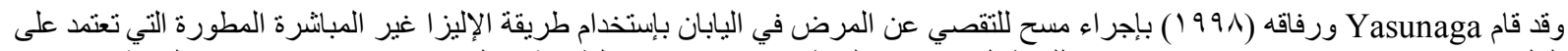

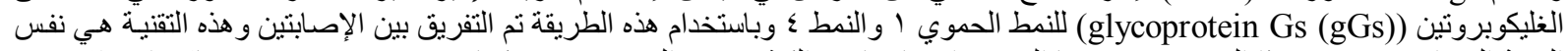

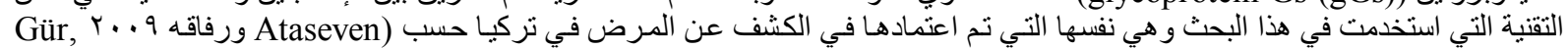

2008).

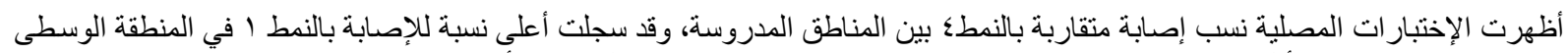

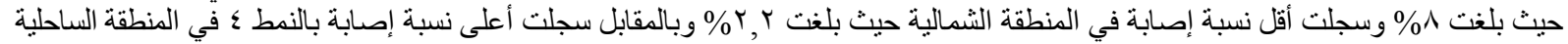
حيث بلغت . . 1\%\%.

لقد كانت نتائج الإختبار مماثلة لتلك التي سجلت في الأبحاث التي جرت مسبقاً في دول مجاورة كتلك التي سجلت في في مناطق قريبة من منطقتئا

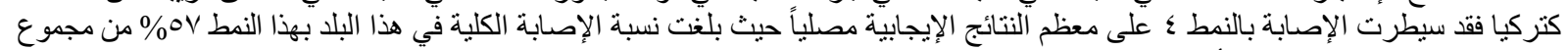

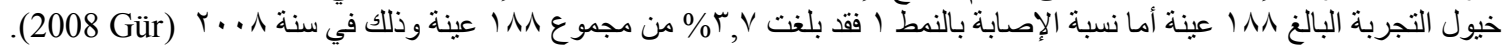

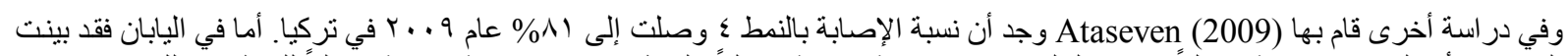

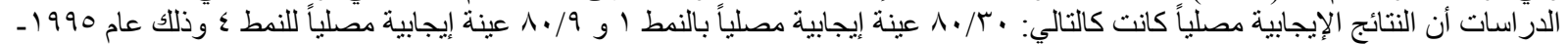
1997 1998 وذلك حسب (1998)

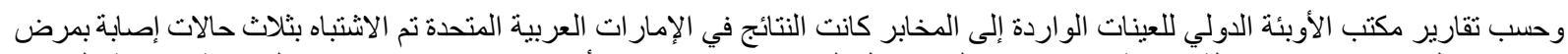

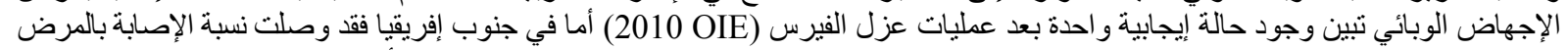

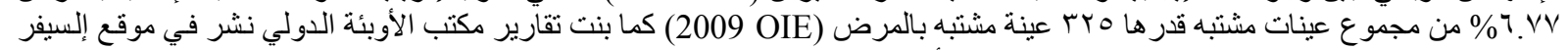

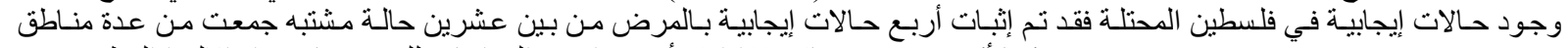
(intl.elsevierhealth.com/journals/trst)

القوباء الخيلية النمطين المصليين / / كانت كل العينات إيجابية للنمط المصلي ع و هذا مأ يتو افق مع النتائج التي حصلنا عليها في هذه الدراسة.

وحسب در اسات أخرى قام بها (Crabb and Studdert, 1993 ; 1994; Gilkerson et al., 1994; Van Maanen et al., 2000) ، فإن إنساب النمط ا يسبب إصابات مرضية أكثر خطورة من الإصابات التي يسببها النمط ع.

\section{CONCLUSIONS}

الاستنتاجـات

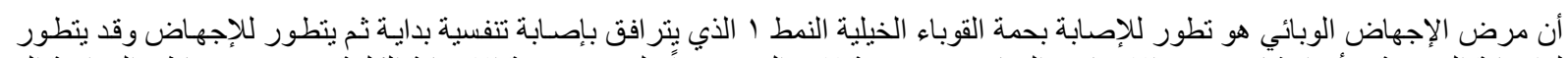

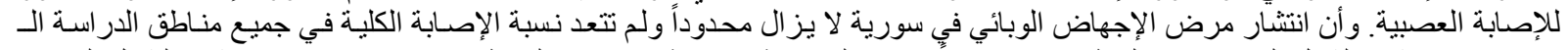

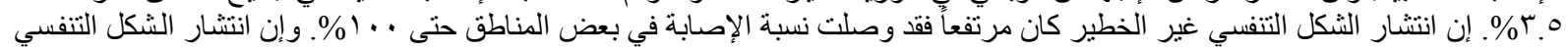

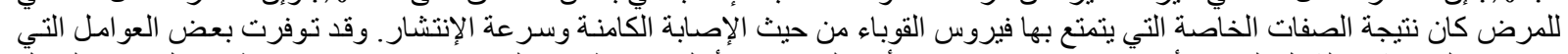

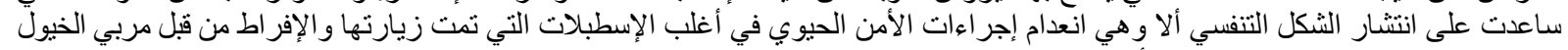

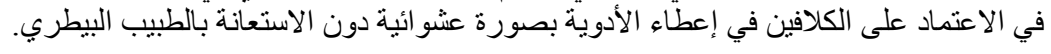

\section{RECOMMENDATION التوصيـات}

ـ وضع هذا المرض على قائمة الأمر اض الطارئة في المعابر الحدودية (نظام التحصين الأول).

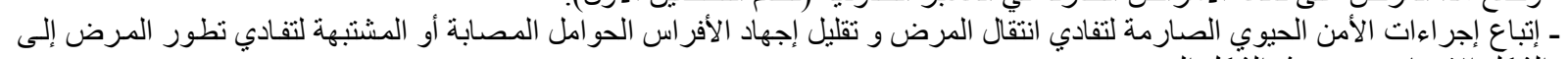

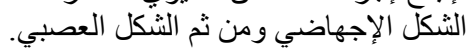
ـ إجر اء در اسات متممة للبحث من حيث تقييم اللقاح المتوفر في بعض بلدان العالم. 


\section{REFERENCES \\ المراجع}

ALLEN, G.P.; KYDD, J.H.; SLATER, J.D. and SMITH, K.C. (1999): Recent advances in understanding the pathogenesis, epidemiology, and immunological control of equid herpesvirus-1 (EHV-1) abortion. Equine Infect. Dis., 8, 129-146.

ALLEN, G.P. and BRYANS, J.T. (1986): Molecular epizootiology, pathogenesis, and prophylaxis of equine herpesvirus-1 infection. in Veterinary Microbiology and Immunology, 2, 78-144.

ATASEVEN, V.S.; DAGALP, S.B.; GüZELM., BASARAN, Z.; TAN M.T. and GERAGHTY, B. (2009): Prevalence of equine herpesvirus- 1 and equine herpesvirus-4 infections in equidae species in Turkey as determined by ELISA and multiplex nested PCR. Res. Vet. Sci., 86(2), 339-44.

BORCHERS, K. and SLATER, J. (1993): A nested PCR for the detection and differentiation of EHV-1 and EHV4. J. Virol. Methods, 45, 331-336.

BRYANS, J.T. and ALLEN, G.P. (1988): Herpesviral diseases of the horse. In: Herpesvirus Diseases of Animals, Wittman G., ed. Kluwer, Boston, USA, 176-229.

BRYANS, J.T. and ALLEN, G.P. (1989): Herpesviral diseases of the horse. In: Herpesvirus Diseases of Cattle, Horses and Pigs, Ed: G. Wittmann, Kluwer, Boston, pp. 176-229.

$C R A B B, B . S$. and, STUDDERT, M.J. (1995): Equine herpesviruses 4 (equine rhinopneumonitis virus) and 1 (equine abortion virus). Adv. Virus Res., 45, 153-190.

$C R A B B, B . S$. and STUDDERT, M.J. (1993): Epitopes of glycoprotein G of equine herpesviruses 4 and 1 located near the c-termini elicit type-specific antibody responses in the natural host. J. Virol., 67, 6332-6338.

$C R A B B, B . S$. and STUDDERT, M.J. (1994): Equine herpesviruses 4 (equine rhinopneumonitis virus) and 1 (equine abortion virus). Adv. Virus Res., 45, 153-190.

CRABB, B.S.; MACPHERSON, C.M.; REUBEL, G.H.; BROWNING, G.F.; STUDDERT, M.J. and DRUMMER, H.E. (1997): Archives of Virology, 140(2), 245-258.

DOLL, E.R. and BRYANS, J.T. (1963): A planned infection program for immunizing mares against viral rhinopneumonitis. Cornell. Vet., 53, 249-262.

DUTTA S.K. and TALBOT N.C. \& MYRUP A.C (1983): Detection of equine herpesvirus-1 antigen and the specific antibody by enzyme-linked immunosorbent assay. Am. J. Vet. Res., 44, 1930 -1934.

EDINGTON, N.; WELCH, H.M. and GRIFFITHS, L. (1994): The prevalence of latent equid herpesviruses in the tissues of abattoir horses. Equine Vet. J., 26, 140-142.

GILKERSON, J.R.; JORM, L.R.; LOVE, D.N.; LAWRENCE, G.L. and WHALLEY, J.M. (1994): Epidemiologic investigation of equid herpesvirus 4 (EHV 4) excretion assessed by nasal swabs taken from Thoroughbred foals. Vet. Microbiol., 39, 275-283.

GILKERSON, J.R.; LOVE, D.N. and WHALLEY, J.M. (1997): Serological evidence of equine herpesvirus 1 (EHV-1) infection in Thoroughbred foals 30-120 days of age. Aust. Equine Vet., 15, 128-134.

$G \ddot{U} R$, S. and YAPICI, O. (2008): Equine Herpesvirus type 1 and 4 in Individually Reared Horses in Central and Western Turkey. Acta Vet. Brno., 77, 609-613.

HARTLEY, C.A.; WILKS, C.R.; STUDDERT, M.J. and GILKERSON, J.R. (2005): Comparison of antibody detection assays for the diagnosis of equine herpesvirus 1 and 4 infections in horses. Am. J. Vet. Res., 66, 921-928.

MATUMOTO, M.; ISHIZAKI, R. and SHIMIZU, T. (1965): Serological survey of equine rhinopneumonitis virus infection among horses in various countries. Arch. Ges. Virusforsch., 50, 609-623.

O'CALLAGHAN, D.J.; GENTRY, G.A. and RANDALL, C.C. (1983): The equine herpesviruses. In: Roizman B, editor. The Herpesviruses. New York: Plenum Press., p. 215-318.

OIE, WWW.oie.int (2009): Information received on 15/12/2009 from Mr Bothle Michael Modisane, Chief Director Food and Veterinary Services, Department of Agriculture, Food Safety and Biosecurity: Department of Agriculture, PRETORIA, South Africa.

OIE, WWW.oie.int (2009): Information received on 20/05/2010 from Eng Sumaia Al Rais, Head of Animal and Plant Health, Animal and Plant Health Department, Ministry of Environment and Water, Dubai, United Arab Emirates.

PATEL, J.R. and HELDENS, J. (2005): Equine herpesviruses 1 (EHV-1) and 4 (EHV-4) - epidemiology, disease and immunoprophylaxis: a brief review. The Veterinary Journal, 170, 14-23.

REED, S.M. and TORIBIO, R.T. (2004): Equine herpesvirus 1 and 4. Veterinary Clinics of North America Equine Practice, 20, 631-642.

SLATER, J. (2007): Equine herpesviruses. In: Sellon, D., Long, M. (Eds.), Equine Infectious Diseases. Saunders Elsevier, St. Louis, USA, pp. 134-153.

STUDDERT, M.J. (1974): Comparative aspects of equine herpesviruses. Cornell. Vet., 64, 94-122.

THOMSON, G.R.; MUMFORD, J.A.; CAMPBELL, J.; GRIFFITHS, L. and CLAPHAM, P. (1976): Serological detection of equid herpesvirus 1 infections of the respiratory tract. Equine Vet. J., 8, 58-65. 
VAN MAANEN, C. (2002): Equine herpesvirus 1 and 4 infections: an update.Veterinary Quarterly, 24, 58-78.

VAN MAANEN, C.; VREESWIJK, J.; MOONEN, P.; BRINKHOF, J.; DE BOER-LUIJTZE, E. and TERPSTRA, $C$. (2000): Differentiation and genomic and antigenic variation among fetal, respiratory and neurological isolates from EHV 1 and EHV 4 infections in the Netherlands. Vet. Q., 22, 88-93.

WELCH, H.M.; BRIDGES, C.G.; LYON, A.M.; GRIFFITHS, L. and EDINGTON, N. (1992): Latent equid herpesviruses 1and 4: detection and distinction using the polymerase chain reaction and co-cultivation from lymphoid tissues. J. Gen. Virol., 73, 261-268.

YASUNAGA, S.; MAEDA, K.; MATSUMARA, T.; KONDO, T. and KAI, K. (2000): Application of a type spesific enzymelinked immunosorbent assay for equine herpesvirus types 1 and 4 (EHV-1 and -4) to horse populations inoculated with inactivated EHV-1 vaccine. J. Vet. Med. Sci., 62, 687-691.

YASUNAGA, S.; MAEDA, K.; MATSUMARA, T.; KAI, K.; IWATA, H. and INOUE, T. (1998): Department of Veterinary Microbiology, Faculty of Agriculture, Yamaguchi University, Japan. Diagnosis and seroepizootiology of equine herpesvirus type 1 and type 4 infections in Japan using a type-specific ELISA. J. Vet. Med. Sci., 60(10), 1133-1137. 